\title{
Reply to comment on: Weickert MO, Pfeiffer AFH (2006) Signalling mechanisms linking hepatic glucose and lipid metabolism. Diabetologia 49:1732-1741
}

\author{
M. O. Weickert • A. F. H. Pfeiffer
}

Received: 25 October 2006 / Accepted: 26 October 2006 / Published online: 7 December 2006

(C) Springer-Verlag 2006

To the Editor: We appreciate the comment from Black and Bell [1] and agree that whilst the results obtained in animal models provide valuable insights, they cannot necessarily be extrapolated to other species [2]. Studies performed in free-living humans and particularly longer-term interventions generally face the problem of potentially confounding factors that cannot be adequately controlled for compared with animal studies. Heterogeneity of subjects is another problem in human studies. Apart from potential species differences (even between rodents), this probably further contributes to diverse findings obtained from studies performed in humans and animals. When investigating molecular pathways in the liver another difficulty arises due to the potential hazards of performing liver biopsies in humans. As such, most available data reporting molecular interactions in the liver are derived from in vitro studies or from animal studies [2].

A number of studies have reported improved peripheral and hepatic insulin sensitivity after treatment with peroxisome proliferator activator receptor- $\alpha(\operatorname{PPAR} \alpha)$ agonists in rodents [3], as well as improved markers of insulin resistance in humans [4]. In contrast and perhaps counterintuitively, PPAR $\alpha$ null mice are protected from insulin resistance and develop fasting hypoglycaemia. As correctly stated by Black

M. O. Weickert $(\bowtie) \cdot$ A. F. H. Pfeiffer

Department of Clinical Nutrition,

German Institute of Human Nutrition Potsdam-Rehbruecke,

Arthur-Scheunert-Allee 114-116,

14558 Nuthetal, Germany

e-mail: m.weickert@dife.de

M. O. Weickert • A. F. H. Pfeiffer

Department of Endocrinology, Diabetes and Nutrition,

Charité-University-Medicine Berlin,

Campus Benjamin Franklin,

Berlin, Germany and Bell, in human intervention studies peripheral insulin sensitivity did not improve after treatment with fibrates, when measured with the euglycaemic-hyperinsulinaemic clamp technique $[5,6]$. Moreover, a recent large study did not detect any effect of fenofibrate on glucose parameters in patients with type 2 diabetes [7]. Even though confounding factors such as significantly increased use of other lipidlowering drugs (mainly statins) in the placebo group may have contributed to this finding, a species-specific effect of PPAR $\alpha$ agonists on glucose metabolism cannot be excluded.

However, activation of PPAR $\alpha$ by fibrates showed improved fasting glucose concentrations in a number of other intervention studies [8]. Improved fasting glucose concentrations after fibrate treatment might reflect improved hepatic insulin sensitivity, which cannot be assessed using euglycaemic-hyperinsulinaemic clamps. Only few longer-term studies have investigated hepatic glucose output after fibrate treatment in humans. In a randomised double-blind controlled study in ten patients with type 2 diabetes no reduction in hepatic glucose output was found [5], and there was also no effect in a study with 13 nondiabetic men [6]. In another study in 12 men with type 2 diabetes, gemfibrozil treatment for 3 months significantly reduced hepatic glucose production in a subgroup of patients defined on the basis of glycaemia values, but not in the entire cohort [9]. In contrast, in a recent study in 18 healthy subjects, basal hepatic glucose production showed a statistically significant improvement of dexamethasoneinduced insulin resistance, when fenofibrate was added to dexamethasone [10], supporting the hypothesis that PPAR $\alpha$ agonists improve hepatic insulin resistance in humans.

Nevertheless, we agree that larger and longer-term well controlled intervention studies using stable isotope techniques and liver biopsies are needed to assess effects of any pharmacological agent on hepatic glucose metabolism in 
humans. Heterogeneity of subjects such as sex-related differences, concomitant medication, dietary factors, and the genetic background need to be taken into account in human studies.

\section{References}

1. Black RNA, Bell PM (2006) Comment on: Weickert MO, Pfeiffer AFH (2006) Signalling mechanisms linking hepatic glucose and lipid metabolism. Diabetologia DOI 10.1007/s00125-006-0550-7

2. Weickert MO, Pfeiffer AFH (2006) Signalling mechanisms linking hepatic glucose and lipid metabolism. Diabetologia 49:1732-1741

3. Chou CJ, Haluzik M, Gregory C et al (2002) WY14,643, a peroxisome proliferator-activated receptor alpha (PPARalpha) agonist, improves hepatic and muscle steatosis and reverses insulin resistance in lipoatrophic A-ZIP/F-1 mice. J Biol Chem 277:24484-24489

4. Tenenbaum A, Fisman EZ, Boyko V et al (2006) Attenuation of progression of insulin resistance in patients with coronary artery disease by bezafibrate. Arch Intern Med 166:737-741
5. Vuorinen-Markkola H, Yki-Jarvinen H, Taskinen MR (1993) Lowering of triglycerides by gemfibrozil affects neither the glucoregulatory nor antilipolytic effect of insulin in type 2 (noninsulin-dependent) diabetic patients. Diabetologia 36:161-169

6. Karhapaa P, Uusitupa M, Voutilainen E, Laakso M (1992) Effects of bezafibrate on insulin sensitivity and glucose tolerance in subjects with combined hyperlipidemia. Clin Pharmacol Ther 52:620-626

7. Keech A, Simes RJ, Barter P et al (2005) Effects of long-term fenofibrate therapy on cardiovascular events in 9795 people with type 2 diabetes mellitus (the FIELD study): randomised controlled trial. Lancet 366:1849-1861

8. Murakami K, Nambu S, Koh H, Kobayashi M, Shigeta Y (1984) Clofibrate enhances the affinity of insulin receptors in non-insulin dependent diabetes mellitus. Br J Clin Pharmacol 17:89-91

9. Shen DC, Fuh MM, Shieh SM, Chen YD, Reaven GM (1991) Effect of gemfibrozil treatment in sulfonylurea-treated patients with noninsulin-dependent diabetes mellitus. J Clin Endocrinol Metab 73:503-510

10. Subramanian S, Derosa MA, Bernal-Mizrachi C et al (2006) PPAR $\alpha$ activation elevates blood pressure and does not correct glucocorticoid-induced insulin resistance in humans. Am J Physiol Endocrinol Metab 291:E1365-E1371 